\title{
The primary care management of anxiety and depression: a GP's perspective ${ }^{\dagger}$
}

\author{
Alan Cohen
}

\begin{abstract}
The management of anxiety and depression in primary care presents significant issues for workload and understanding the patient in terms of a bio-psychosocial model. There is no shortage of policy in this area, but finding effective and innovative ways of implementing that guidance is only just beginning. This article discusses some of the ways that implementation is happening for adults of working age.
\end{abstract}

This is not a clinical treatise on the latest management of depression and anxiety; indeed it would be an interesting example of 'teaching grandmother to suck eggs' for a general practitioner (GP) to be writing for psychiatrists on this topic. I am concerned here more with the implementation of best practice, and how current policy and developments are influencing care. I have, however, written from an unashamedly general practice perspective, giving the opinion of many GPs with whom I have spoken.

Ihave also written about policy and implementation in England. The situation in other countries within the UK is subtly different, most importantly as regards acceptance of guidelines published by the National Institute for Health and Clinical Excellence (NICE). Certainly Scotland and Northern Ireland, while acknowledging these guidelines, do not necessarily subscribe to them. Scotland, for example, has its own well-respected SIGN guidelines for mental health, produced by the Scottish Intercollegiate Guidelines Network (www.sign.ac.uk/guidelines/index.html). Nevertheless, the new GP contract described below applies to all four countries.

\section{How common are depression and anxiety?}

Depression and anxiety are clearly common and disabling. The World Health Organization (Murray \& Lopez, 1997) has predicted that depression will be the second most common disabling condition (after

${ }^{\dagger}$ For an editorial and a commentary on this article see pp. $84-85$ and $106-108$, this issue.

ischaemic heart disease) worldwide by 2020 . They are also conditions frequently encountered in primary care; it is estimated (Goldberg \& Huxley, 1980) that up to a third of the 280 million consultations in primary care annually (Royal College of General Practitioners, 2006) have a significant mental health component.

Findings of the survey of psychiatric morbidity among adults living in private households in Great Britain (Office for National Statistics, 2001) allow an estimation of the number of people with depression or anxiety likely to occur in a specific population. As an example, Table 1 shows the likely numbers

Table 1 The prevalence of different mental health conditions by population size

Prevalence by population

$\begin{array}{lrcr}\text { Disorder } & 500000 & 50000 & 10000 \\ \text { Psychotic illness } & 1340 & 134 & 26.8 \\ \begin{array}{l}\text { Mixed anxiety and } \\ \text { depression }\end{array} & 30820 & 3082 & 616.4 \\ \text { Generalised anxiety } & 15745 & 1574.5 & 314.9 \\ \text { Depressive episode } & 9380 & 938 & 187.6 \\ \text { All phobias } & 6365 & 636.5 & 127.3 \\ \text { OCD } & 4020 & 402 & 80.4 \\ \text { Panic disorder } & 2345 & 234.5 & 46.9 \\ \text { All neuroses } & 57955 & 5795.5 & 1159.1 \\ \text { Drug dependence } & 14070 & 1407 & 281.4 \\ \text { Alcohol dependence } & 27135 & 2713.5 & 542.7 \\ \text { OCD, obsessive-compulsive disorder. } & & \\ \text { Source: Office for National Statistics, 2001. } & \end{array}$

Alan Cohen was a GP for 25 years in Mitcham, south London, before joining Kensington and Chelsea Primary Care Trust as Clinical Director (April 2004 to May 2005). Since 2005 he has been Primary Care Advisor to the Care Services Improvement Partnership and he remains in active clinical practice. He also works as Senior Fellow at the Sainsbury Centre for Mental Health (134-138 Borough High Street, London SE1 1LB, UK. Email: Alan.cohen@scmh.org.uk). He was Chair of the London Development Centre for Mental Health, one of the eight regional development centres of the National Institute of Mental Health in England. 
in populations of 500000 - the new primary care trust (PCT) average population, 50000 - the average population for a community mental health team (CMHT), and 10000 people - an average general practice. The Table also shows, for comparison, prevalence of other mental disorders.

Given these statistics, it is not surprising that depression and anxiety are common presentations in general practice, and that their management represents an important part of the work of primary care services.

Depression and anxiety often coexist with other long-term clinical conditions and, more importantly, affect their outcome. Thus, depression is more common in people with diabetes, and management of the depression improves the control of the diabetes (Goldney et al, 2004). Depression is a common sequela of chronic pain, and management of the pain requires effective management of the depression; likewise, effective management of the depression requires that the pain be controlled.

Common mental illnesses affect not only the mental and physical health of individuals; they also affect their ability to function within society. Data on the relationship between employment and mental illness are particularly telling (Waddell \& Burton, 2006):

- in any one year, 3 in 10 people of working age take sick leave because of mental illness

- 91 million working days are lost annually to mental illness

- about 1 million people are on long-term sick leave because of mental illness and are receiving incapacity benefit

- fewer than $10 \%$ of these individuals are in contact with specialist mental health services

- the proportion returning to employment, after having been on incapacity benefit for 12 months or more, is less than $5 \%$.

Management of people with such a complex set of interacting conditions requires a generalist with access to evidence-based interventions, so that the most effective and coordinated care is provided.

\section{National policy}

Policy issues relating to primary care mental health have been raised only relatively recently. By far the most important piece of policy that relates to primary care is the National Service Framework (NSF) for Mental Health (Department of Health, 1999).

\section{The NSF for Mental Health}

The NSF for Mental Health sets out quite clearly, among other priorities, that it is the role of the specialist mental health trusts to prioritise people with severe mental illnesses (which GPs perceive as almost always meaning psychotic illness). It is not appropriate to discuss here the definition of severe mental illness, nor the appropriateness of the priority placed on specialist mental health trusts; it is, however, appropriate to consider the consequences of this decision and how it has affected clinical services.

\section{The National Service Framework: a barrier to referral...}

The clear priority placed on severe mental illness caused CMHTs, and the subsequent 'functional' teams, to set up clear access criteria for referrals made from primary care. Although the rationale for such criteria seemed clear to those delivering the care, the perspective from general practice was that specialist mental health services were withdrawing services, becoming less accessible and less part of mainstream care.

The Policy Implementation Guide for Community Mental Health Teams (Department of Health, 2000a) made clear the role that they should play in working with primary care services, and how CMHTs should provide a consultation service to general practice. Nevertheless, the experience of GPs was that the shift to functional teams was carried out at the expense of CMHTs, as staff were moved from the generic teams into the new units. General practitioners felt that the personal relationship built up with individual psychiatrists and practice-attached community psychiatric nurses was being undermined, as CMHTs attempted to manage larger and larger areas. The CMHTs became smaller as the new functional teams started up; GPs had to relate not only to the CMHT, but to the crisis resolution team, and the assertive outreach team and the rehabilitation team, and to learn which team was responsible for which type of patient. It seemed to GPs that people whom they were not confident to manage were being denied a specialist opinion.

\section{... and a barrier to treatment}

In so far as depression and anxiety were concerned, it was clear that psychological therapy services were an important evidence-based intervention. Access to these services, run by specialist mental health trusts, was via referral to CMHTs, yet patients with anxiety and depression did not meet the newly described access criteria for the CMHTs or the functional teams. Thus, a direct consequence of the NSF setting out so clearly the priority that specialist mental health trusts should provide care to people with severe mental illness was that other mentally ill patients were denied reasonable access to a service that primary care could not provide. 
At the time, primary care services did not have alternatives: GP fundholding was being abolished and practice-based commissioning (discussed below) had not yet been introduced. From a primary care perspective, people who needed an evidence-based intervention - psychological therapy - were being denied it because they were not ill enough. General practitioners felt that they were being accused either of making many inappropriate referrals to specialist services, or prescribing too many antidepressants inappropriately. They found themselves between a rock and a hard place - there were patients that they knew they could not manage with confidence in primary care, yet they were unable to refer for a specialist opinion. And whatever clinical line they chose, it would be likely not to provide the best outcome for the patient, and neither would it improve relationships between primary and secondary care. This really had to be the most unplanned consequence of a clear and, at first sight, appropriate policy decision.

\section{Graduate primary care mental health workers}

In an effort to address what was becoming a significant problem for primary care, and more so for the vast number of people being denied access to evidencebased care, the concept of the graduate primary care mental health worker (Box 1) was introduced in the National Health Service (NHS) Plan (Department of Health, 2000b) and subsequently supported by bestpractice guidance (Department of Health, 2003).

The outcomes of this initiative have been reviewed by Harkness et al (2005), who found that:

- fewer mental health workers than planned were employed, although the distribution across the country was variable; $40 \%$ of those interviewed reported that they intended to seek work elsewhere in the NHS;

- about two-thirds managed patients, but access was often restricted (half of patients were reviewed by a mental health professional);

- types of patients seen, and interventions provided, were generally in line with current guidelines;

- the degree of integration into primary care settings of individuals trained in mental health environments was a significant predictor of their success.

\section{Clinical care}

In 2004 NICE published clinical guidelines on the management, in primary and secondary care, of depression (National Collaborating Centre for Mental

\section{Box 1 Graduate primary care mental health} workers

The Department of Health's promises

- 'One thousand new graduate primary care mental health workers, trained in brief therapy techniques of proven effectiveness, will be employed to help GPs manage and treat common mental health problems in all age groups, including children...

- ...By 2004, more than 300000 people will receive extra help from the new primary care mental health workers' (Department of Health, 2000b: p. 119)

- '[Funds will be provided] sufficient to employ two or three new graduate workers in each PCT according to need, and to retain them ' (Department of Health, 2003: p. 4)

To achieve this, guidance (Department of Health, 2003) was published to:

- 'help primary care trusts ... appoint at least 1000 new graduate primary care workers by $2004^{\prime}$ (p. 3)

- 'support the delivery of an integrated mental health service, building on the strengths that already exist, to ease pressure on GP services and improve the quality and outcomes for service users' (p. 11)

Health, 2004) and anxiety (McIntosh et al, 2004). The guidelines represent the best available analysis and practical interpretation of current evidence, providing for the first time frameworks for the management of these conditions in the NHS in England.

\section{The management frameworks}

\section{Stepped care}

The evidence collated in the NICE depression guidelines informed the development of a stepped care model to guide management of the disorder (Fig. 1). This framework represents a major advance: it clearly states who should provide what sort of care to treat depression presenting at different levels of severity and risk.

\section{Choice of interventions}

Stepped care did not prove suitable for the management of anxiety. The NICE anxiety guidelines report no evidence, for example, that mild generalised anxiety disorder should be managed any differently from the severe disorder. Nevertheless, the evidence base revealed three effective interventions for generalised anxiety disorder or panic disorder, and 


\begin{tabular}{|c|c|c|c|c|}
\hline & \multicolumn{2}{|c|}{ Who is responsible for care? } & What is the focus? & What do they do? \\
\hline & & $\begin{array}{r}\text { Step } 5 \text { In-patient care, } \\
\text { crisis teams }\end{array}$ & $\begin{array}{l}\text { Risk to life, } \\
\text { severe self-neglect }\end{array}$ & $\begin{array}{l}\text { Medication, } \\
\text { combined treatments, } \\
\text { ECT }\end{array}$ \\
\hline & Step 4 & $\begin{array}{r}\text { Mental health } \\
\text { specialists, } \\
\text { including crisis teams }\end{array}$ & $\begin{array}{l}\text { Treatment-resistant, recurrent, } \\
\text { atypical and psychotic depression, } \\
\text { and those at significant risk }\end{array}$ & $\begin{array}{l}\text { Medication, complex } \\
\text { psychological interventions, } \\
\text { combined treatments }\end{array}$ \\
\hline & Step 3 & $\begin{array}{r}\text { Primary care team, } \\
\text { primary care } \\
\text { mental health worker }\end{array}$ & Moderate or severe depression & $\begin{array}{l}\text { Medication, } \\
\text { psychological interventions, } \\
\text { social support }\end{array}$ \\
\hline & tep 2 & $\begin{array}{r}\text { Primary care team, } \\
\text { primary care } \\
\text { mental health worker }\end{array}$ & Mild depression & $\begin{array}{l}\text { Watchful waiting, guided self-help, } \\
\text { computerised CBT, exercise, } \\
\text { brief psychological interventions }\end{array}$ \\
\hline Step 1 & \multicolumn{2}{|r|}{ GP, practice nurse } & Recognition & Assessment \\
\hline
\end{tabular}

Fig. 1 The stepped care model (National Collaborating Centre for Mental Health, 2004: p. 52).

that offering the patient a choice of intervention improves the likelihood that it will be successful. This approach was presented as the framework for the management of anxiety.

\section{A mixed message?}

One of the criticisms that I heard levelled at the guidelines is that clinical experience, supported by Office for National Statistics data, indicates that the most common presentation is a combination of anxiety and depression: having separate frameworks for the management of these conditions serves only to confuse clinicians and patients alike.

Both NICE guidelines recognise that the two disorders present in combination, but resolve this problem by recommending that the depressive element be managed first, and once the depression has lifted, that the anxiety be tackled. A review of this approach is overdue, as it is not clear that the evidence points to this as the most effective strategy. It is interesting that neither guideline group reviewed any papers that intentionally compared the different approaches to managing mixed anxiety and depression; the advice was based solely on clinical experience. It is perhaps a failing of research practice that some of the most important questions in clinical practice cannot be easily answered using current research methods.

\section{Recommended interventions}

Although the two guideline groups recommend a different organisational approach to the management of depression and of anxiety, the types of intervention recommended are very similar and fall into four main categories: watchful waiting, self-help, psychological therapy, medication.

\section{Watchful waiting}

Also known as active review, this interesting intervention requires no more (nor less) than active follow-up of individuals who may have depression, or who have depression that is perceived to be mild. As reported in the NICE depression guidelines, a significant proportion of people with depression recover spontaneously, without medical intervention. One of the principles of a stepped care approach to the management of depression is that the least burdensome intervention should be used, and if that is just active review, then that is entirely appropriate. Individuals are recalled at regular short intervals for reassessment. It may be that at subsequent consultations the condition has resolved, or deteriorated, or the individual is more accepting of the diagnosis. (Acceptance of a diagnosis is an important part of the success of any intervention: offering a person an intervention for a disorder that they do not believe they have is not likely to make that intervention successful.)

Together, watchful waiting and patients' denial may in large part explain a frequently quoted but misunderstood statement about mental health in primary care: that GPs identify only $50 \%$ of people with a mental health condition (Goldberg \& Huxley, 1980). (It seems a little unfair to criticise GPs in a study that compared their success in identifying mental health disorder during a 10 minute consultation with that of research psychiatrists who administered a 60 minute gold-standard questionnaire.)

General practitioners realise that time is an important part of the consultation process, and that reviewing the patient after a couple of weeks may well provide more information and a clearer clinical picture. This is watchful waiting. Furthermore, during this time the patient may become more accepting of the diagnosis and thus more amenable to help. 


\section{Self-help}

This group of interventions includes computerised cognitive-behavioural therapy (computerised CBT), structured exercise programmes, bibliotherapy (written materials, manuals) and, for depression, counselling and watchful waiting. Changes to the diet may also be helpful for people with depression (Mental Health Foundation, 2006).

Computerised CBT was recently reviewed by NICE (National Institute for Health and Clinical Excellence, 2006), and just one programme for depression was approved for use in the NHS in England - Beating the Blues. The significance of a technology appraisal is that PCTs are now required to provide the intervention, so since 1 April 2007, they have had to provide this particular programme. The technology appraisal was interesting in that it did not review two 'free to access' programmes, one from Australia called MoodGym (moodgym.anu.edu. $\mathrm{au}$ ) and one from Scotland called Living Life to the Full (www.livinglifetothefull.com). It is not yet clear whether these programmes are as effective as Beating the Blues, or offer cost-effective alternatives.

Many PCTs offer exercise on prescription for people with chronic obstructive pulmonary disease and ischaemic heart disease, as part of their rehabilitation. The NICE guidelines report strong evidence that exercise is also effective for people with depression and anxiety, and that this may present a more acceptable form of intervention for some.

Counselling has been shown to be effective for mild depression (National Collaborating Centre for Mental Health, 2004), and for many GPs this is an important intervention. As mental health trust services have become more distant and harder to access, owing to implementation of the NSF on Mental Health, many primary care practices have employed their own counsellors to offer onsite mental health advice. This delivers easily and quickly accessed advice. Although many counsellors engaged by practices are fully qualified, the dangers of an unregulated profession, without a required national registration process and without regular professional supervision, are becoming clearer. A recent White Paper (Department of Health, 2006) made clear the need for regulation of counsellors in general practice. Many PCTs have responded to this issue by ensuring that the counsellors they employ adhere to clinical standards.

\section{Psychological therapy}

The NICE guidelines reflect a very strong evidence base that cognitive-behavioural therapy is effective in generalised anxiety disorder, panic disorder and depression. There is also evidence that most patients would prefer a talking therapy (Department of Health, 2006). However, accessing this service from primary care is particularly difficult and usually involves long waiting times. This is compounded by the fact that most psychotherapy services are run by specialist mental health trusts, which have to prioritise patients with severe mental illness. The GP faces an unacceptable choice: to offer the patient a talking-therapy intervention in 9-12 months' time, or to offer medication now. From the patient's perspective it is equally frustrating a talking therapy delivered some time in the future, or medication, which has received extensive bad publicity, now.

As the current Chair of the Royal College of General Practitioners Mayur Lakhani (2006) points out, criticising GPs for providing poor care is not conducive to improving the situation. Hopefully, the Improving Access to Psychological Therapies programme (see below) might remedy the situation.

\section{Medication}

For patients who choose medication, the guidelines recommend selective serotonin reuptake inhibitors (SSRIs) for the treatment of generalised anxiety and panic disorders and moderate or severe (not mild) depression.

Note that NICE has recently amended guideline advice on the use of venlafaxine (National Institute for Health and Clinical Excellence, 2007). The main changes to the anxiety guideline concern the use of pharmacotherapy and the considerations that need to be taken into account before prescribing venlafaxine. The main changes to the depression guideline are on the use of antidepressants especially in patients with cardiovascular disease and the considerations that need to be taken into account when switching treatment to venlafaxine.

\section{Applying the theory}

Although it is enormously helpful to have clear guidelines on the management of depression and anxiety in primary care, the test to apply to any clinical guideline is whether or not its implementation improves care.

\section{The GP contract and QOFs}

To that end it is worth spending a little time discussing the new GP contract (NHS Employers, 2004). Less than $10 \%$ of GPs are salaried - the vast majority are self-employed. In 2004, following 2 years of negotiation, a new contract was introduced for GPs seeing patients within the NHS. This differed 
from previous contracts in a number of important ways, but so far as this discussion is concerned, the major difference was the introduction of the 'quality and outcomes framework' (QOF). The QOF provides GPs with a financial incentive to deliver high-quality, evidenced-based essential care. Essential care defined for the first time in the 2004 contract - is the care that all general practices are expected to provide. To incentivise the quality of that care a framework was developed that accounts for about $20 \%$ of a GP's earnings.

The concept underpinning the QOF is that points are awarded to each practice for the delivery of specified processes or outcomes in four domains: clinical, organisational, patient care experience, and additional services. Each point has a financial value. Outcomes are specified and evidence based, and in view of the fact that the evidence base changes and develops over time, the QOF is reassessed every 2 years to review new research and to make changes where appropriate.

In the clinical domain, outcomes relate to the management of various clinical (mostly long-term) conditions, for each of which a number of indicators are specified. Achieving each indicator is rewarded with points from the total number available for that condition. It should not be forgotten that the new GP contract would be for all GP practices offering services under the NHS, and that remuneration and earnings would be related to aspects of care. It was therefore imperative that the indicators were specific, recordable on practice computer systems and accurately described the care provided, and also that the opportunity for 'gaming' (completing the indicators but not completing the intent and purpose of the clinical intervention) was minimised.

Depression was not among the conditions listed in the clinical domain in the first QOF in 2004. However, in the 2006 revision (NHS Employers \& General Practitioners Committee, 2006), extensive changes were made to the mental health indicators, and depression was allocated its own share of points. In the 2006/7 QOF, 1000 points were available, of which 655 related to the clinical domain (Box 2).

The two indicators for depression (Box 3) were drawn directly from the NICE depression guidelines - a good example of the process of moving from research, to the review of evidence (through the NICE guidelines development process), to engagement (by the creation of a specific QOF domain based on the depression guidelines). These indicators are the only two that the expert clinicians, negotiators and administrators involved developing the GP contract believed could accurately be introduced for depression. The experts were unable to develop an indicator that linked the intervention offered to the severity of the depression - although this

\begin{tabular}{|c|c|}
\hline Condition & Points \\
\hline Coronary heart disease & 89 \\
\hline Diabetes mellitus & 93 \\
\hline Heart failure & 20 \\
\hline Hypertension & 83 \\
\hline Smoking indicators & 68 \\
\hline Asthma & 45 \\
\hline Mental health & 39 \\
\hline $\mathrm{COPD}^{1}$ & 33 \\
\hline Depression & 33 \\
\hline Atrial fibrillation & 30 \\
\hline Chronic kidney disease & 27 \\
\hline Stroke or transient ischaemic attack & 24 \\
\hline Dementia & 20 \\
\hline Epilepsy & 15 \\
\hline Cancer & 11 \\
\hline Obesity & 8 \\
\hline Hypothyroidism & 7 \\
\hline Pallative care & 6 \\
\hline Learning disabilities & 4 \\
\hline Total & 655 \\
\hline
\end{tabular}

is a natural next step in the development of the depression QOF.

The impact of the inclusion of depression in the clinical domain is hard to judge, since it has only

Box 3 Allocation of the 33 QOF points awarded for 'depression'

- 8 points for recording the percentage of patients on the diabetes register and/or the coronary heart disease register assessed for depression at least once during the previous 15 months using two standard screening questions on the Patient Health Questionnaire 2 (PHQ-2)

- 25 points for recording the percentage of patients with a new diagnosis of depression (recorded between the preceding 1 April to $31 \mathrm{March}$ ) assessed for severity of depression at the outset of treatment using the PHQ-9, the Beck Depression Inventory Second Edition (BDI-II) or the Hospital Anxiety and Depression (HAD) scale

(After NHS Employers \& General Practitioners Committee, 2006) 
had a year of implementation. If the depression indicators are accepted by GPs, the UK will be the first country in the world in which primary care clinicians routinely use questionnaires to assess severity of depression and link this to an appropriate intervention

An interesting by-product of the QOF process is that (in theory) every practice now records the same data, which are downloaded to the PCT, and hence to a central virtual warehouse of data, to provide evidence for payment. This warehouse could provide enormously valuable information about a whole range of clinical conditions, including depression, indicating for example the proportions of people with mild, moderate and severe depression - data that are currently unavailable.

\section{The relationship with specialist services}

Thus far I have focused on the role of primary care services in delivering care for people with anxiety and depression. In fact up to $90 \%$ of people with mental health problems are managed entirely in primary care (Department of Health, 1999). However, there are a small number of patients whose condition is so serious that care needs to be provided by specialist services. Accurate identification of these individuals is an essential task for GPs and their teams.

In the case of depression the stepped care model (Fig. 1) makes that identification a more structured and logical process. Steps 4 and 5 clearly indicate which patients should be managed by specialist services: those who have treatment-resistant, recurrent, atypical or psychotic depression, who show severe self-neglect or are actively suicidal. The correct identification of these individuals depends on the clinical skills of the referring GP. However, to expect every referral for depression from every GP to fall into one of these categories is unrealistic.

From a primary care perspective there are four reasons why an individual may be referred to a specialist (of any particular clinical type):

- the GP does not know what to do and wants advice about:

- the diagnosis, or

- management

- the GP knows what to do - but cannot do it

- the patient has requested a second opinion

- there is a need to transfer or share care in some formalised fashion.

The last reason would encompass, for example, the shared care of someone with bipolar disorder, where shared monitoring of lithium might be appropriate.

\section{Improving access to psychotherapy}

As already mentioned, one of the major difficulties with providing evidence-based care from general practice is the accessibility of CBT and other forms of talking therapy. The Improving Access to Psychological Therapies (IAPT) Programme, a joint initiative of the Department of Health and Care Services Improvement Partnership (CSIP), is a pilot project aimed at remedying that problem in England. Much has already been written about IAPT, and interested readers are directed to the CSIP website for up-to-date information (www.mhchoice. csip.org.uk/psychological-therapies/psychologicaltherapies.html).

On World Mental Health Day 2007, the Secretary of State for Health announced significant new funding for IAPT in England (Johnson, 2007). From April 2008, £30m would be made available, increasing to $£ 100 \mathrm{~m}$ in 2009 , then $£ 170 \mathrm{~m}$ in 2010 . This new resource will be used to set up psychological therapy centres, which will provide both local treatment for patients and training for new therapists. Further details can be found at the IAPT home page on the CSIP website (www.mhchoice.csip.org.uk).

\section{Practice-based commissioning}

Practice-based commissioning (Department of Health, 2004), an improvement on the discredited (for mental health) GP fundholding scheme, offers an excellent opportunity to redesign the delivery of psychological therapies. For discussion of how practice-based commissioning could be used to commission mental health services, including psychological therapies, readers are directed to the CISP website (commissioning pages of www. mhchoice.csip.org.uk/psychological-therapies / psychological-therapies.html) and the Royal College of General Practitioners' new textbook on primary care mental health (Cohen, 2008).

\section{Conclusions}

The NICE guidelines on the management of depression and anxiety reveal the clear link between evidence, guidelines and implementation. This is particularly transparent for depression, where a logical stepped care model directs treatment from primary care to specialist services. Delivery of the NICE recommendations for psychotherapeutic interventions in primary care is not so easy, but it is to be hoped that efforts being made to improve access to talking therapies involving the IAPT programme and practice-based commissioning will supplement the effective implementation of improved care. 
Through best-practice guidance linked to financial incentives, contractual changes and innovative commissioning processes, there is at last a real opportunity to improve care for people with depression and anxiety managed in primary care.

\section{Declaration of interest}

None.

\section{References}

Cohen, A. (2008) Delivering Mental Health in Primary Care: An Evidence-based Approach. Royal College of General Practitioners.

Department of Health (1999) The National Service Framezork for Mental Health: Modern Standards and Service Models for Mental Health. UK Department of Health.

Department of Health (2000a) Policy Implementation Guide for Community Mental Health Teams. UK Department of Health.

Department of Health (2000b) The NHS Plan: A Plan for Investment, A Plan for Reform. UK Department of Health.

Department of Health (2003) Fast-Forwarding Primary Care Mental Health: Graduate Primary Care Mental Health Workers. Best Practice Guidance. UK Department of Health.

Department of Health (2004) Practice Based Commissioning: Engaging Practices in Commissioning. UK Department of Health (http:/ / www.dh.gov.uk/en/Publicationsandstatistics/Publications/ PublicationsPolicyAndGuidance/DH_4090357).

Department of Health (2006) Our Health, Our Care, Our Say. TSO (The Stationery Office).

Goldberg, D. \& Huxley, P. (1980) Mental Illness in the Community: The Pathway to Psychiatric Care. Tavistock Publications.

Goldney, R. D., Phillips, P. J., Fisher, L. J., et al (2004) Diabetes, depression, and quality of life: a population study. Diabetes Care, 27, 1066-1070.

Harkness, E., Bower, P., Gask, L., et al (2005) Improving primary care mental health: survey of evaluation of an innovative workforce development in England. Primary Care Mental Health, 3, 253-260.

Johnson, A. (2007) Speech in the House of Commons, by Rt Hon Alan Johnson MP, Secretary of State for Health, 10 October 2007: NHS Interim Review. UK Department of Health (http:/ / www. dh.gov.uk/en/News/Speeches/DH_079340).

Lakhani, M. (2006) RCGP Comment on MIND Ecotherapy Report. Royal College of General Practitioners (http: / www.rcgp.org. uk/news_events/news_room/news_releases_and_press_ statem/2007_mind_report_ecotherapy.aspx).

McIntosh, A., Cohen, A., Turnbull, N., et al (2004) Clinical Guidelines and Evidence Review for Panic Disorder and Generalised Anxiety Disorder. University of Sheffield/National Collaborating Centre for Primary Care (http://guidance.nice.org.uk/ CG22/?c=91523)

Mental Health Foundation (2006) Healthy Eating and Depression. How Diet May Help Protect Your Mental Health. Mental Health Foundation.

Murray, C. J. \& Lopez, A. D. (1997) Alternative projections of mortality and disability by cause 1990-2020: Global Burden of Disease Study. Lancet, 349, 1498-1504.

National Collaborating Centre for Mental Health (2004) Depression: Management of Depression in Primary and Secondary Care. Clinical Guideline 23. NICE (http://guidance.nice.org. $\mathrm{uk} / \mathrm{CG} 23 / \mathrm{c}=91523)$

NHS Employers (2004) Investing in General Practice. The New General Medical Services Contract. London

NHS Employers \& General Practitioners Committee (2006) Revisions to the GMS Contract 2006/07. Delivering Investment in General Practice. NHS/BMA. (http://www.bma.org.uk/ ap.nsf/Content/revisionnGMSFeb20062).

National Institute for Health and Clinical Excellence (2006) Computerised Cognitive Behaviour Therapy for Depression and Anxiety. Review of Technology Appraisal 51 (Technology Appraisal TA97). NICE (http:/ / www.nice.org.uk/guidance/TA97).
National Institute for Health and Clinical Excellence (2007) Press Release: NICE Amends Depression and Anxiety Guidance in Line with Safety Recommendations. NICE (http:/ / www.nice.org.uk/ niceMedia/pdf/2007022DepressionAndAnxietyUpdate.pdf).

Office for National Statistics (2001) Psychiatric Morbidity among Adults Living in Private Households, 2000. TSO (The Stationery Office).

Royal College of General Practitioners (2006) Key Demographic Statistics from Uk General Practice: July 2006. RCOGP (http:/ / www.rcgp.org.uk/pdf/ISS_FACT_06_KeyStats.pdf).

Waddell, G. \& Burton, A. K. (2006) Is Work Good for Your Health and Well-Being? TSO (The Stationery Office).

\section{MCQs}

1 According to the WHO, the most common disabling condition in the world by 2020 will be:

a ischaemic heart disease

b depression

c anxiety

d diabetes

e chronic obstructive pulmonary disease.

2 Of the following, depression is most commonly associated with:

a diabetes

b warts

c COPD

d URTI

e IGTN.

3 The proportion of people off work because of mental illness and in contact with specialist mental health services is:

a $<10 \%$

b $20 \%$

c $40 \%$

d $60 \%$

e $90 \%$.

4 The role of graduate mental health workers for adults includes:

a mental health assessment

b ECT

c guided self-help

d CBT

e prescribing medication.

5 The conditions listed within the QOF clinical domain do not include:

a COPD

b anxiety

c depression

d diabetes

e mental health.

\begin{tabular}{|c|c|c|c|c|}
\hline \multicolumn{5}{|c|}{ MCQ answers } \\
\hline 1 & 2 & 3 & 4 & 5 \\
\hline a $\mathrm{T}$ & a $\mathrm{T}$ & a $\mathrm{T}$ & a $F$ & a $F$ \\
\hline b F & b F & b F & b F & $\mathrm{b} T$ \\
\hline c F & c F & C F & c $\mathrm{T}$ & c F \\
\hline d F & d F & d F & d F & d F \\
\hline e $F$ & e $F$ & e F & e $F$ & e $F$ \\
\hline
\end{tabular}

